\title{
OLHARES, XINGAMENTOS E AGRESSÕES FÍSICAS: A PRESENCA E A (IN)VISIBILIDADE DE CONFLITOS REFERENTES ÀS RELACÕES DE GÊNERO EM ESCOLAS PÚBLICAS DO RIO DE JANEIRO
}

\author{
Ana Paula Mendes de Miranda* \\ Bóris Maia** \\ Universidade Federal Fluminense - Brasil
}

Resumo: Tomando por objeto conflitos referentes às relações de gênero ocorridos em escolas públicas do estado do Rio de Janeiro, pretende-se contrastar a visibilidade da temática das relações de gênero na esfera pública com a invisibilidade que tal temática adquire no cotidiano das escolas públicas. Observa-se que os conflitos que ocorrem na escola são classificados como "problemas de disciplina", sendo muitas vezes associados a práticas de discriminação de gênero, que se manifestam como parte constitutiva das sociabilidades escolares. A partir da descrição de dois casos de conflitos de gênero, busca-se mostrar os agentes envolvidos, os discursos mobilizados e a forma institucional pela qual foram administrados pela equipe técnico-pedagógica da escola. Os dados apresentados derivam de uma pesquisa realizada em diferentes escolas públicas do estado do Rio de Janeiro, nas quais as atividades escolares foram acompanhadas a partir de trabalho de campo e observação participante.

Palavras-chave: administração de conflitos, escola pública, gênero, sociabilidade escolar.

* Contato: ana_paulamiranda@yahoo.com.br

** Doutorando em Antropologia (bolsista Capes). Contato: borismaias@gmail.com 


\begin{abstract}
Focused on conflicts related to gender relations that occur at public schools in the state of Rio de Janeiro, this paper aims to contrast the visibility of gender relations in the public sphere with the invisibility that this issue gets in schools routine. Several conflicts that occur at schools and are classified as "discipline problems" are often associated with sexual discrimination practices that manifest themselves as a constituent part of the school sociability. Based on the description of cases of gender conflicts, it seeks to show the agents involved, the discourses mobilized and the institutional forms in which they were managed by the school's staff. The data presented are derived from a research conducted in different public schools in the state of Rio de Janeiro, in which school activities were accompanied from fieldwork and participant observation.
\end{abstract}

Keywords: conflicts administration, gender, public school, school sociability.

\title{
Introduç̃o
}

A escola é uma instituição de grande influência na delimitação de identidades de gênero em nossa sociedade, embora não seja a única. Nela podemos observar situações consideradas "normais”, que explicitam visões de mundo, tais como a ideia de que a carreira docente do ensino fundamental/médio é um trabalho majoritariamente feminino, que por sua vez é desqualificado em relação a outras atividades profissionais. ${ }^{1}$ Também não há estranhamento que a divisão de tarefas e atividades se dê entre meninos e meninas, do mesmo modo que as cores dos materiais didáticos, os uniformes, os equipamentos e a escolha das brincadeiras na hora do recreio são definidos por estereótipos de gênero ligados à masculinidade, à feminilidade e à sexualidade. Consequentemente, há uma naturalização no interior da escola sobre as manifestações de comportamentos adquiridos na socialização familiar, valorizada como principal e primeira, que

1 Segundo Prá e Cegatti (2016) a feminização de determinadas carreiras profissionais está associada a diversos fatores, tais como as demandas das mulheres por acesso à educação e ao mercado laboral, que exigiram a superação do desafio de conciliar as obrigações femininas derivadas da maternidade e das funções domésticas, resultando na escolha de algumas carreiras que possibilitam tal flexibilidade, como é o caso da docência no ensino fundamental e médio. Para as autoras, a consequência desse processo expressa, em diferentes países, situações como a infrarrepresentação das mulheres em postos decisórios ou a precarização dos salários. A feminização seria, portanto, resultado de um processo de "segregação horizontal" associado à concentração de mulheres em atividades entendidas socialmente como "femininas”, que resulta na "segregação vertical”, revelada pelas dificuldades em alcançar postos superiores na hierarquia profissional. Tal processo produz uma desqualificação do ofício docente no ensino básico.

Horizontes Antropológicos, Porto Alegre, ano 23, n. 49, p. 177-202, set./dez. 2017 
não deveria ser alterado pela escola. ${ }^{2}$ Assim, a reprodução de modelos hegemônicos de gênero passa despercebida, sem que os atores se deem conta de que os conhecimentos e representações construídas, no âmbito das práticas escolares, produzem zonas de visibilidade (manifestações verbais, visuais e comportamentais) e zonas de invisibilidade (moralidades e crenças) (Nóvoa, 1990).

Pouco se sabe sobre como os conflitos referentes às relações de gênero se desenrolam na escola e de que maneira o tema é tratado pelos diferentes atores. O propósito deste trabalho é justamente contribuir nessa direção, a partir de dados resultantes de pesquisas de campo em diferentes espaços escolares. ${ }^{3}$ Tomando por objeto conflitos referentes às relações de gênero ocorridos em escolas públicas, em diferentes regiões do estado do Rio de Janeiro, pretendemos contrastar a visibilidade da temática das relações de gênero na esfera pública $^{4}$ com a invisibilidade que tal temática adquire no cotidiano das escolas públicas.

O “aprendizado da separação” (Auad, 2006) construído no cotidiano escolar por meio de atividades pedagógicas e lúdicas acaba por revelar a existência de diferenças, polaridades e assimetrias de gênero, que resultam numa invisibilização dos conflitos associados às relações de gênero na escola. Tal fato ocorre apesar do crescimento do debate sobre o tema no campo da educação (Fagundes, 2001; Louro, 1995; Louro; Neckel; Goellner, 2003). O crescimento

2 Parte da discussão em torno da "ideologia de gênero" na escola tem a ver com a prerrogativa dos pais e da família em “educar” seus filhos no que se refere às questões de gênero e de sexualidade. O tema será tratado mais adiante no texto, mas aqui optamos apenas por ressaltar que o termo "ideologia de gênero" está associado ao documento produzido pela Conferência Episcopal Peruana, em 1998, intitulado "La ideología de género sus peligros y alcances”, e mais recentemente à publicação do livro Ideologia de gênero - neototalitarismo e a morte da família, de autoria do advogado argentino Jorge Scala, que se tornou uma referência para os católicos ativistas, tendo sido traduzido para o português por uma editora católica, a Katechesis, em 2011. O tema resultou em um pacto entre católicos e evangélicos num lobby religioso, protagonizado principalmente por deputados evangélicos, no Brasil, durante a discussão do Plano Nacional de Educação.

3 Referimo-nos a dois projetos de pesquisa desenvolvidos a partir de 2013: “Conflitos de gênero no ambiente escolar: repensando as formas de administração de conflitos”, coordenado por Ana Paula Mendes de Miranda, e "Construindo uma educação de qualidade: análise das expectativas e obstáculos quanto à transformação do ensino público no Estado do Rio de Janeiro”, coordenado por Simoni Lahud Guedes. Ambos contaram com financiamento da Faperj. Os referidos projetos foram desdobramentos de outras pesquisas realizadas em contextos de escolas públicas no Rio de Janeiro.

4 Parte dessa visibilidade é motivada pela controvérsia em torno de denúncias pelos movimentos sociais do aumento de crimes relacionados às questões de gênero (feminicídios, mortes motivadas por transfobia, etc.), bem como do enfrentamento de tais movimentos com grupos que defendem o fim da "ideologia de gênero" na escola.

Horizontes Antropológicos, Porto Alegre, ano 23, n. 49, p. 177-202, set./dez. 2017 
de pesquisas sobre identidade de gênero ${ }^{5}$ e sobre a elaboração e implantação de diversas políticas públicas com recorte de gênero, a partir da década de 1980, teve como princípios a defesa da diversidade sexual e o enfrentamento à violência doméstica e à discriminação, tendo como públicos-alvo preferenciais as mulheres e os grupos discriminados em função de sua identidade de gênero.

A incorporação da perspectiva de gênero por toda política pública, de forma transversal e por meio de políticas específicas, alcançou o campo educacional (Rosistolato, 2007), e tem resultado na aprovação de leis - em âmbito nacional, estadual e municipal - que colocam em primeiro plano o debate sobre como a "diversidade de gênero" tem sido tratada na escola. Assim, é possível encontrar esse termo figurando como princípio em diversos documentos oficiais destinados a orientar, instruir e esclarecer a prática pedagógica nas escolas - como os Parâmetros Curriculares Nacionais, a proposta da Base Nacional Curricular Comum, ${ }^{6}$ resoluções e portarias aprovadas pelas secretarias de educação, manuais de orientação publicados por órgãos ligados à educação, entre outros -, processo que tem sido denominado como “ascensão da diversidade” (Abramowicz; Rodrigues; Cruz, 2011). Ainda assim, quando se consideram as principais legislações, em especial, a Constituição Federal de 1988, a Lei de Diretrizes e Bases da Educação Nacional (LDB) e o atual Plano Nacional de Educação (PNE), ${ }^{7}$ percebe-se que há pouca referência à diversidade e às identidades de gênero e sexualidade.

A primeira vez que o conceito de gênero apareceu em documentos públicos foi nos Parâmetros Curriculares Nacionais (Brasil, 1998), como um tema transversal no documento intitulado "Orientação sexual”. A intenção era tratar da sexualidade como algo inerente à vida e à saúde, que se expressa no ser humano do nascimento até a morte. Todavia, mesmo com grande destaque dado à questão biológica e prevenção de doenças, houve a introdução de temas que, ainda hoje, são considerados controversos, tais como o direito ao prazer e ao exercício da sexualidade com responsabilidade; as relações de gênero; o respeito a si mesmo e ao outro; a diversidade de valores e manifestações culturais.

\footnotetext{
Consideramos que a identidade de gênero é o produto de processos de identificação em ambientes de relações de poder desiguais (Vale de Almeida, 2003).

6 Os documentos provisórios podem ser acessados em http://basenacionalcomum.mec.gov.br/\#/site/inicio (acesso em 24/09/2016).

Dita as diretrizes e metas da educação para os próximos dez anos.
} 
Recentemente, observou-se outra controvérsia em torno da "ideologia de gênero”, que começou quando, em 2011, o Fundo Nacional de Desenvolvimento da Educação (FNDE) fez um convênio para o desenvolvimento do projeto "Escola sem Homofobia", como desdobramento do programa "Brasil sem Homofobia", lançado em 2004 pelo governo federal. A elaboração de um material didático, que seria distribuído às instituições de todo o país, foi objeto de questionamento no Congresso Nacional, onde se iniciou uma campanha contra o material, chamado pejorativamente de "kit gay". Tal conflito voltou ao debate público envolvendo o anteprojeto de lei "programa escola sem partido", ${ }^{8}$ que é resultado de uma mobilização social contra a suposta "doutrinação em sala de aula", e tem dominado a cena política.

Ainda que os desdobramentos com relação às disputas em torno da política educacional sejam imprevisíveis, podendo haver um cenário de revisão das legislações baseadas no discurso de valorização da diversidade, é fato que essas controvérsias têm trazido visibilidade às questões de gênero no âmbito da educação pública.

Os documentos da política educacional antes citados mostravam-se inspirados por um conceito de gênero tal como o proposto por Joan Scott (1989), ${ }^{9}$ para quem as formas culturais de construção de percepção sobre as diferenças sexuais constituem um modo básico de organizar as relações de poder, podendo resultar na hierarquização das categorias de gênero de um modo engessado e dual, bem como pelas ideias de Judith Butler (2003), para quem o uso da categoria de gênero pode ser um limitador da luta política contra a discriminação sexual, uma vez que a dicotomia sexo-natureza/gênero-cultura acaba resultando em outras posturas deterministas (Bessa, 1995). Embora a discussão de gênero tenha sido incorporada aos documentos que deveriam nortear as políticas públicas educacionais, o tema das relações de gênero está também presente no currículo formal da escola, com conteúdos ou objetivos sugeridos a serem trabalhados em cada disciplina. Todavia, na prática há obstáculos presentes no cotidiano da escola, seja nas atividades pedagógicas, seja nos momentos livres.

8 Trata-se de uma proposta de lei que torna obrigatória a afixação de cartaz, em todas as salas de aula do ensino fundamental e médio, com os seis deveres do professor, que seria uma resposta ao "abuso da liberdade de ensinar”. Disponível em http://www.programaescolasempartido.org/ (acesso em 20/07/2016).

9 Vale ressaltar que o texto de Joan Scott foi traduzido para o português por um periódico da área da educação (ver Scott, 1995). 
Julgamos relevante esclarecer que o gênero foi considerado como uma variável relevante para compreender os conflitos no ambiente escolar já que compõe o processo de construção identitária de crianças e jovens, possibilitando compreender como as relações entre os sujeitos se dá, a partir da oposição entre feminilidade/masculinidade, bem como outras formas de manifestação da sexualidade.

\section{A administração de conflitos nas escolas: um tema antropológico}

A socialização de crianças e jovens em instâncias de educação formal ainda está longe de ser uma preocupação central dos antropólogos no Brasil, embora haja contribuições desde o final dos anos 1990 no sentido de delimitação de um campo de pesquisa, que poderia ser denominado como antropologia da educação ${ }^{10}$ (Dauster, 1997, 2008; Guedes, 2014; Gusmão, 1997, 2010; Nanes; Leitão; Quadros, 2016; Tosta, 2011).

A perspectiva adotada neste texto pretende destacar um ângulo das relações entre antropologia e educação que se relaciona às práticas e saberes, formais ou não, constituídos nas interações entre os profissionais e estudantes no cotidiano escolar. Nesse sentido, tomamos a escola como um espaço privilegiado para análises antropológicas, tendo em vista que a instituição tem uma importância central na definição de identidades em sociedades ocidentais, que se apresentam como modernas e democráticas, ao mesmo tempo em que é palco de explicitação de diferenças e desigualdades, que ultrapassam as fronteiras dos muros da escola.

Isso coloca em perspectiva a crença na eficácia da escola que, geralmente, é associada ao seu papel de integração cultural (Bourdieu, 1987). Ao assumir o compromisso político de construir os “cidadãos”, a escola incorpora duas funções simultâneas - a transmissão de saberes e a socialização. Consequentemente, ao desempenhar esses papéis, a escola possibilita o desenvolvimento de formas de sociabilidade que propiciam a construção de um corpo comum de categorias de percepção, de pensamento e de ação a partir de experiências vividas na instituição.

10 Além das referidas publicações, esse esforço também pode ser notado a partir da presença constante nos últimos anos de grupos de trabalho e mesas-redondas sobre a temática nas mais prestigiadas reuniões científicas de antropologia no Brasil e na América Latina, como a Reunião Brasileira de Antropologia, a Reunião de Antropologia do Mercosul e o Congreso Latinoamericano de Antropología.

Horizontes Antropológicos, Porto Alegre, ano 23, n. 49, p. 177-202, set./dez. 2017 
Resende (2010) argumenta que a intervenção da escola no mundo ocidental contemporâneo tem se desenvolvido a partir de duas orientações aparentemente contraditórias. A primeira delas se refere ao investimento numa educação crítica, questionadora, voltada para formar indivíduos autônomos e autorrealizáveis. A outra tem como objetivo a unidade e a consolidação de um projeto de Estado-Nação, cujo objetivo é a construção de uma ética republicana e de uma identidade nacional. Assim, a criação dessa "forma escolar moderna” (Vincent, 1994 apud Resende, 2010) produziria consequências na configuração das relações sociais em função do seu modo de socialização e transmissão de saberes. Ao pretender converter as crianças e os jovens em cidadãos, a escola pode colocar em choque distintos modelos de sociabilidade no que se refere à construção de identidades pessoais e pertencimentos socais, que implicam a definição de gostos e valores.

Por serem incipientes, no Brasil, as abordagens que priorizam a dimensão das sociabilidades, principalmente no que se refere à construção de relações de amizade e dos grupos de afinidades, bem como à produção de estigmas e estereótipos no espaço escolar, poucos são os trabalhos que privilegiam a administração de conflitos no ambiente escolar.

A presença dos conflitos sociais na dinâmica das instituições escolares, porém, já fora destacada por análises sobre a socialização escolar em pesquisas de viés mais empírico e etnográfico, como a desenvolvida por Jackson (1968), que enfatizou que as relações entre professores e alunos na escola tendem a ser potencialmente conflituosas, já que ambos não partilham de objetivos e interesses comuns no cotidiano da instituição escolar. Na mesma direção, Becker (2013, p. 3) sentenciou: “Crianças não querem ir para a escola, mas os adultos as obrigam a ir, de modo que o estado natural das relações sociais na escola é o conflito.”

O esforço em descrever as situações de resistência escolar - o que os trabalhos de Willis (1991) e McLaren (1992) fizeram com grande destaque cumpriu um papel importante na discussão sobre as relações de poder vivenciadas ao longo do processo educativo que se desenrola no âmbito da escola, mostrando como o questionamento à autoridade dos professores pode se dar de múltiplas formas, gerando conflitos no cotidiano escolar.

Ainda assim, a maioria das proposições de quadros de referência para o estudo etnográfico de escolas e de demais aparatos institucionais de ensino, como as de Erickson (1984), Ogbu (1981) e Fischer (1980), não faz referência 
explícita aos conflitos como uma das unidades de análise relevantes para a compreensão dos processos sociais vivenciados por aqueles que estabelecem relações e interações cotidianas nesses espaços.

Os estudos sobre gênero apontam que a instituição escolar é um dos espaços centrais para se compreender a organização das relações de gênero na contemporaneidade (Connell; Messerschmidt, 2013; Martino, 1995; Warren, 1997), cuja construção é frequentemente marcada por violências que atingem alunos e professores (Mac An Ghaill, 1994; Welzer-Lang, 2001), indicando a importância dos conflitos de gênero no processo educacional.

Mais particularmente sobre o contexto do Rio de Janeiro, os conflitos envolvendo religião no ambiente escolar já têm sido identificados e descritos (Caputo, 2012; Maia, 2014a; Miranda, 2015; Miranda; Maia, 2014), revelando como as escolas públicas ainda se relacionam com dificuldade com a diversidade religiosa de seu público.

Vale ressaltar que entendemos o conflito a partir da abordagem formulada por Simmel (1983), de reprodução de ações interativas e relacionais sociais, que pode possibilitar momentos tanto de construções quanto de destruições de situações sociais. Portanto, ao colocar em evidência os conflitos vivenciados nas escolas, buscamos superar uma concepção de conflito que o associa a algo diruptivo da ordem social, impedindo de ver as relações que se instituem a partir de situações conflituosas.

Como afirma Luís Roberto Cardoso de Oliveira (2010, p. 457), a

etnografia dos conflitos supõe um esforço de compreensão das interações entre as partes, com respaldo na experiência delas, de modo a viabilizar a atribuição de um sentido que esclareça o desenrolar do conflito e/ou da relação.

O modo pelo qual as instituições administram os conflitos vivenciados no seu interior está ligado às diferentes tradições socioculturais das quais estão embebidas, formatando dispositivos de controle social que são acionados pelos agentes em seu contexto de atuação (Kant de Lima, 1999, 2001). No caso das escolas, uma análise centrada nos conflitos e em sua administração institucional permite entender o tipo de socialização de gênero a que os estudantes são submetidos, já que se trata de uma instituição com fins explicitamente pedagógicos.

Como pretendemos argumentar neste trabalho, vários dos conflitos que ocorrem na escola e são classificados como "problemas de disciplina” muitas 
vezes estão associados também a práticas de discriminação de gênero, que se manifestam como parte constitutiva das sociabilidades escolares, seja na relação entre pais e professores, entre professores e alunos, e entre alunos.

Situados entre o ensino fundamental e médio, os estudantes estão em pleno processo de construção de suas identidades de gênero, o que significa que é vivenciado no ambiente escolar um conjunto de disputas e enfrentamentos, de rivalidades e associações que explicita moralidades situacionais (Eilbaum, 2012), ou seja, revela valores e interesses associados às histórias de vida, às relações sociais, às perspectivas de mundo e às posições institucionais.

Como qualquer processo de construção identitária, a identidade de gênero se constitui por meio da expressão de conflitos e tensões entre os diferentes atores que são por eles afetados. A escola transforma-se, assim, numa arena onde emergem diversos problemas de gênero (Butler, 2003), conformando e instituindo diferentes modelos de masculinidade e feminilidade que podem, ou não, gerar conflitos entre si.

Consequentemente, o gênero é uma variável relevante para analisar a dinâmica escolar, interferindo tanto na maneira como as aulas transcorrem quanto no interesse dos alunos e sua participação nas atividades escolares, ou seja, na qualidade do processo de ensino-aprendizagem.

\section{Presença e (in)visibilidade dos conflitos referentes às relacōoes de gênero}

Os dados que iremos apresentar são resultado de investigações levadas a cabo em 15 escolas ${ }^{11}$ com perfis diferenciados: 2 de educação infantil/ensino fundamental, 8 de ensino médio, e 5 que atendiam ao ensino fundamental e médio; entre todas elas, 7 também atuavam no EJA (Educação de Jovens e Adultos).

${ }^{11}$ Centro Integrado de Educação Pública (Ciep) Aarão Steinbruch - Duque de Caxias; Centro Integrado de Educação Pública (Ciep) Candido Portinari - Duque de Caxias; Centro Integrado de Educação Pública (Ciep) Maria Joaquina de Oliveira - Seropédica; Centro Integrado de Educação Miécimo da Silva Rio de Janeiro; Colégio Estadual Dr. Albert Sabin - Rio de Janeiro; Colégio Estadual Barão de Tefé Seropédica; Colégio Estadual Manoel de Abreu - Niterói; Colégio Estadual Princesa Isabel - Petrópolis; Colégio Estadual Sargento Antônio Ernesto - Nova Iguaçu; Colégio Estadual Visconde do Rio Branco Campos dos Goytacazes; Escola Estadual Doutor Memória - Niterói; Escola Municipal Rostham Pedro de Farias - Rio de Janeiro; Escola Técnica Estadual Henrique Lage - Niterói; Escola Técnica Estadual João Barcelos Martins - Campos dos Goytacazes; Instituto de Educação Rangel Pestana - Nova Iguaçu. 
Foram envolvidos 28 pesquisadores, ${ }^{12}$ dos quais 5 atuam também como professores da rede pública de ensino. O trabalho privilegiou a observação das aulas e demais atividades nas escolas, como a hora do recreio no pátio e em outras áreas de convivência em que a dimensão das sociabilidades dos estudantes podia ser mais bem observada.

A equipe desenvolveu etnografias buscando compreender o cotidiano escolar, as relações sociais e os sentidos atribuídos à instituição pelos distintos sujeitos que a constituem. Assim foi possível evidenciar como os conflitos se manifestavam no ambiente escolar, em especial, aqueles relacionados às questões de gênero, presentes nas interações entre estudantes, professores e funcionários, mas invisíveis no que se refere aos significados e quadros de referências (Goffman, 2012) partilhados, ou não, entre esses atores. As experiências dos sujeitos em relação aos conflitos de gênero estão diretamente associadas às realidades nas quais eles estão inseridos. Consequentemente, são as situações cotidianas que organizam e articulam as interpretações dos sujeitos, no plano dos acontecimentos e das subjetividades. Independentemente das visões de mundo, divergentes ou não, os conflitos constituem uma situação de compartilhamento das interações interpessoais.

Nesse sentido, a escola foi pensada aqui como uma arena pública (Cefaï, 2002), ou seja, um lugar de interações e vivências, que representa um complexo e rico cenário, no qual os atores colocam à prova suas múltiplas competências (citadinas, cívicas, morais, etc.) para a administração de seus conflitos. É também o palco de ações e mobilizações coletivas de grupos que tentam dar visibilidade às suas demandas e reconhecimento de direitos, permitindo que um repertório de problemas venha a se tornar público, legítimo, visível e pertinente aos olhos dos distintos agentes que compõem e perfazem o espaço público (Mota, 2014). A visibilidade ou invisibilidade das ações coletivas revelam, desse modo, a existência de determinadas gramáticas, moralidades e interesses que orientam as ações e as justificativas formuladas pelos agentes diante das controvérsias, ${ }^{13}$ possibilitando a legitimação de

${ }_{12}$ Participaram do projeto estudantes de graduação, pós-graduação e professores vinculados a Universidade Federal Fluminense, Universidade Federal Rural do Rio de Janeiro e Universidade Estadual do Norte Fluminense.

${ }^{13}$ Paula Montero (2012, p. 178) compreende as controvérsias como processos de produção de novas significações no plano discursivo, "por diferentes agentes sem a necessidade de supor que eles estão todos disputando no interior de um mesmo campo e que manejam visões de mundo de um só campo".

Horizontes Antropológicos, Porto Alegre, ano 23, n. 49, p. 177-202, set./dez. 2017 
seus argumentos e viabilizando, ou não, a sua explicitação e seu reconhecimento como problema público.

Ao longo das pesquisas pudemos observar que, no dia a dia da escola, o tema mais comentado estava associado à infraestrutura, no que se refere aos equipamentos e ao espaço físico, seus usos e problemas. O segundo mais relevante tinha a ver com os processos relativos à organização da escola, especialmente, no que tange ao processo educativo (ausência de professores, indisciplina dos alunos, aulas “desmotivantes”, etc.), bem como à inexistência de processos dialógicos ${ }^{14}$ que incluíssem os estudantes na administração dos problemas vivenciados na instituição.

Paradoxalmente, um dos temas de que menos se fala nas escolas é dos que mais provocava conflitos, como pudemos verificar durante o trabalho de campo. E dentre os conflitos, os que menos são enfrentados de forma institucional estão associados às questões de gênero. A seguir descreveremos dois casos que nos parecem exemplares para entender a dinâmica desses conflitos em escolas, buscando mostrar os agentes envolvidos, os discursos mobilizados e a forma institucional pela qual foram administrados pela equipe técnico-pedagógica da escola.

\section{Olhares, xingamentos e agressões}

Durante o recreio de uma escola de ensino médio da região metropolitana, uma confusão se formava no pátio. Em meio a gritos dos estudantes que a presenciavam, formou-se um círculo de espectadores, no centro do qual se desenrolava a mais nova "briga” da escola envolvendo três alunos: Dayane, Gabriel e Leandro. ${ }^{15}$ Gabriel e Dayane, na época, tinham acabado de terminar o namoro, e Dayane já estava “saindo” com outro aluno da escola, Leandro - que viria a ser seu futuro namorado. A estudante foi abordada por Gabriel enquanto falava com Leandro no pátio durante o recreio. Os dois começaram uma discussão. Dayane disse que não lhe devia mais satisfações e Gabriel,

\footnotetext{
14 Tal reclamação representa um aspecto importante da socialização política na escola, na medida em que expressa também uma dificuldade de relação dos estudantes com os professores, que se limitariam ao papel de "transmissores de conteúdos".

15 Todos os nomes são fictícios, mas as identidades de gênero foram mantidas.
} 
então, deu um tapa no rosto dela. Leandro logo se envolveu defendendo Dayane e iniciou uma briga com Gabriel.

Logo após o ocorrido, os alunos envolvidos foram levados à direção. Dayane contou o caso à diretora, explicando que tinha sido agredida fisicamente por Gabriel. Depois de ouvir o relato da estudante, a diretora disse a ela que "isso era normal de acontecer em relacionamentos", e que a própria Dayane "devia ter provocado o menino", em algum momento, para que ele tivesse "perdido a cabeça”. Ao ouvir a fala da diretora, ainda agitada com o incidente, Dayane respondeu com xingamentos de cunho sexual, bastante ofensivos. Em função dessa reação com a diretora, os pais de Dayane foram chamados à escola e foi assinado por eles um termo de responsabilidade, que determinava que qualquer advertência que a aluna recebesse na escola faria com que ela fosse imediatamente transferida para outra unidade escolar do estado. Gabriel não sofreu nenhuma sanção formal, mesmo assim ficou 15 dias sem ir à escola por recomendação da diretora, que depois descobrimos ser sua tia. O parentesco dos dois foi enfatizado por Dayane, que também ficou algum tempo sem ir à escola, dizendo-se humilhada com o que tinha acontecido.

Ao retornar à rotina, os conflitos entre Dayane e Gabriel não cessaram. Apesar de atribuir algumas qualidades positivas a Gabriel, ressaltando o fato de ser "muito inteligente", Dayane contava que ele era muito ciumento. O mesmo ocorria com a nova namorada dele, Sophia, com quem Dayane tinha os maiores problemas no cotidiano escolar. Segundo Dayane, Sophia já havia declarado para vários alunos que desejava vê-la "morta”, e que uma vez teria entrado correndo na escola com uma faca nas mãos à sua procura. Dayane disse que evitava ficar perto dela e que na rua sempre tomava cuidado, pois tinha receio que Sophia a empurrasse contra os carros e ônibus em alta velocidade. Dayane dizia que Sophia temia que ela e Gabriel tivessem "alguma coisa” novamente, pois Sophia considerava que Dayane ainda queria "alguma coisa” com o ex-namorado.

No dia da entrega das camisas de turma do $3^{0}$ ano, ${ }^{16}$ Dayane foi acusada por Sophia de se insinuar para Gabriel. Depois de colocar a camisa que tinha acabado de receber do representante de turma, Dayane percebeu que a

${ }_{16}$ As turmas de $3^{\circ}$ ano do ensino médio da escola em questão podiam fazer uma camisa personalizada, que era aceita como uniforme para os alunos dessas turmas. 
ela estava muito apertada. Sabendo pelo mesmo representante que não teria outra para trocar, começou a reclamar e tirou a camisa na frente dos alunos da turma, ficando de sutiã enquanto pegava a blusa que estava vestindo anteriormente. Sophia acusou Dayane de ter feito tal coisa só para "provocar" sexualmente Gabriel, que estava presente no momento.

Dayane contava que Sophia, às vezes, ficava chorando pela escola, dizendo ter sido provocada por ela. A provocação se daria através do "olhar". Sophia acusava Dayane de ficar encarando-a quando as duas se cruzavam pelos corredores ou pela sala, de "olhar estranho", "olhar torto”, o que Dayane negava.

A briga entre Gabriel e Dayane e a inimizade desta com Sophia acabou redefinindo a própria rede de amizade das duas na escola. Tamires, que era a melhor amiga de Sophia, reprovou a atitude agressiva ${ }^{17}$ de Gabriel e se aproximou de Dayane, o que fez com que ela e Sophia deixassem de se falar. Com o passar do tempo, Tamires se tornaria a melhor amiga de Dayane na escola e ganharia a inimizade de Sophia. Dayane dizia que, depois que Tamires virou sua amiga, Sophia ficava chamando as duas de "vagabundas" pela escola, dizendo que ambas eram "falsas santas".

A escolha de narrar o caso de Dayane justifica-se por ele reunir vários elementos que explicitam grande parte dos conflitos de gênero que identificamos nas escolas pesquisadas. Em primeiro lugar, é importante chamar atenção para o fato de que os conflitos entre as "meninas" nas escolas, como o que envolvia Dayane, Sophia e Tamires no caso descrito, ocorriam com uma frequência muita alta. As agressões entre as estudantes não se limitam aos "puxões de cabelo”, sendo marcadas por socos, chutes e pontapés, o que já havia sido notado em outras escolas por Vargas (2010), podendo incluir também o uso de armas brancas, como facas e canivetes, tal como ocorreu na situação envolvendo Dayane e Sophia, embora não se tenha chegado, nesse caso, às vias de fato.

A presença da violência física nas escolas está associada sobretudo às brigas entre os estudantes, embora os casos envolvendo alunos e professores

17 Bernard Charlot (2002) diferencia os conceitos de agressão, agressividade e violência. O primeiro corresponde a um ato de brutalidade física ou verbal contra alguém, enquanto a agressividade seria uma disposição biopsíquica reacional, provocada pelas frustrações que sofremos no cotidiano. Por fim, a violência está associada ao uso da força, que resulta em formas de destruição simbólica e/ou de humilhação, tendo como consequência uma forma de dominação do “outro” em situações de agressão. 
obtenham mais repercussão pública. As brigas ocorrem principalmente próximo à entrada da escola, em regiões limítrofes com a rua, e nas áreas de convivência da instituição, como o pátio e os corredores. Geralmente, as motivações envolvem razões pessoais (a disputa por namorados, ofensas à família, críticas ao estilo, fofocas, discriminação, xingamentos, “olhares”, etc.). É relevante destacar que os conflitos entre estudantes se apresentem mais explicitamente nessas áreas de fronteira, já que há uma representação corrente de que é permitida a expressão pública de sentimentos na rua, de uma maneira distinta da que se espera em outros espaços sociais, em especial, na escola. Encontramos também casos de ofensas e violência física sofridas por estudantes LGBT dentro do ambiente escolar, como ocorreu no caso de Bruno, que passamos a relatar.

Um grupo de alunos agrediu Bruno fisicamente na escola, com chutes e socos em diferentes partes de seu corpo. Depois das agressões, Bruno ainda foi jogado numa lixeira pelo grupo de alunos e chamado de "gayzinho". Mesmo após reclamar com a coordenadora de turno e com a direção da escola, nenhuma providência foi tomada. A justificativa dada pela direção foi que 0 próprio Bruno, que sofreu a agressão, é que tinha provocado o acontecido devido à maneira pela qual se comportava. Uma das alunas da escola, com quem falamos sobre o ocorrido com Bruno, deu uma resposta bem semelhante, dizendo que o aluno usava calças muito apertadas e tinha gostos musicais exóticos. Na época, Bruno cursava o $1^{\circ}$ ano do ensino médio.

Perguntado sobre as razões que explicavam a existência das agressões, Bruno falou que a escola era como se fosse uma "cadeia alimentar, os mais fortes atacam os mais fracos”. Já no $3^{\circ}$ ano, Bruno considerava estar entre os "fortes", de acordo com a classificação que propunha, diferentemente de quando chegou à escola: "Eu agora estou no topo da cadeia.” Sustentava sua posição de destaque entre os alunos dizendo que era o diretor da rádio, o presidente do grêmio, e que as pessoas, portanto, precisavam falar com ele quando necessitavam de alguma coisa na escola. Contou o caso de um aluno que fazia bullying com ele na época em que era um novato na escola e que depois precisou de sua ajuda. Bruno disse que, então, se "vingou” de seu antigo algoz, "simplesmente ignorando ele".

Em termos das sociabilidades escolares é nítido como grande parte dos conflitos em escolas está associada às piadas, brincadeiras, jogos, apelidos, insinuações e expressões desqualificantes, que podem atingir tanto os estudantes 
quanto os profissionais que atuam na escola. As agressões e brigas entre os alunos no ambiente escolar muitas vezes se iniciam quando a masculinidade ou feminilidade são colocadas em questão através de apelidos e jocosidades (Radcliffe-Brown, 1978) que os próprios alunos atribuem a seus colegas.

De fato, o processo de generificação ${ }^{18}$ se impõe por meio de uma pedagogia sexual em que os sujeitos são socializados em práticas que visam conceber e moldar os modelos hegemônicos de ser masculino e feminino (Connell; Messerschmidt, 2013). No contexto brasileiro, para se transformar em um "macho", os meninos são submetidos a frequentes testes de masculinidade com brincadeiras que violam partes sagradas do corpo masculino (DaMatta, 1997), enquanto das mulheres se espera a docilidade, o recato e a discrição (Louro, 2000).

A inadequação a tais modelos de gênero socialmente aprovados é sempre alvo de sanções por parte dos grupos e instituições que os promovem. Como demonstra Welzer-Lang (2001), as múltiplas formas de violência são um meio comum de manutenção e regulação do universo simbólico que sustenta as relações de dominação de gênero.

Ao tratar das percepções sobre violência em escolas públicas, Pinto (2014) mostrou que a maioria dos casos citados entre as "meninas" estava relacionada ao que chamou de xingamentos morais, como "piranha" e "vagabunda", cujo objetivo era promover uma desqualificação em função de seus supostos comportamentos sexuais. No mesmo sentido, a partir de um estudo sobre a circulação de imagens íntimas de alunas em escolas de ensino médio, Petrosillo (2016) chamou atenção para o caráter humilhante que a sexualidade feminina adquire no contexto escolar.

Não é à toa que, em ambos os casos narrados anteriormente, os alunos que sofreram as agressões físicas, Dayane e Bruno, sofreram também agressões verbais, respectivamente, "falsa santa” e "gayzinho", que fazem referência a comportamentos de gênero que expressam um tipo de feminilidade e masculinidade julgados pela comunidade escolar como ofensivos e repugnantes.

$\mathrm{O}$ caso de Bruno mostra como o aprendizado do gênero masculino no interior da instituição escolar é marcado pelo controle dos próprios alunos sobre o modelo de masculinidade a ser seguido. Tal controle implica orientar

18 Sobre o processo de generificação, ver Butler (2000). 
os meninos a repelir traços associados às mulheres, tidas como hierarquicamente inferiores, já que isso os tornaria menos homens. Cria-se assim uma relação de dominação não apenas dos homens sobre as mulheres, mas também entre os homens, estabelecendo masculinidades hegemônicas e subordinadas (Connell; Messerschmidt, 2013; Vale de Almeida, 1995; Welzer-Lang, 2001).

Embora tenham sofrido as agressões verbais e físicas, ambos são vistos como sendo os causadores dos conflitos nos quais se envolveram, já que seus comportamentos foram inadequados, por isso "provocaram" aqueles que supostamente foram os agressores. Nesse sentido, é importante ressaltar que o discurso da provocação foi utilizado como justificativa por alunos e pela equipe técnico-pedagógica da escola. A presença das ofensas e agressões sofridas por Dayane e Bruno, bem como a estratégia das autoridades (coordenação e direção) de adiar o enfrentamento do conflito, ao optarem por não se envolver diretamente na administração dos casos, faz com que os estudantes sejam alertados para a rígida oposição e hierarquização entre os sexos, associados cada qual a modelos de masculinidade e feminilidade, assim como obrigá-los a seguir os padrões à risca, sob pena de estarem sujeitos às mais diversas arbitrariedades.

Os professores LGBT também são alvo constante desse tipo de ofensas, inclusive vinda de alunos também LGBT, o que torna a questão ainda mais complexa. Esses professores, em função da forma como são tratados pelos alunos durante as aulas, demonstraram ter dificuldade em "manter o controle" de suas turmas, sobretudo quando as ofensas vinham por meio de insinuações e jocosidades (Maia, 2014b). Em algumas situações, diga-se de passagem, os professores são responsáveis por colocar em dúvida a orientação sexual ${ }^{19}$ dos estudantes (Miranda, 2015).

Os xingamentos na maior parte dos casos estão associados à sexualidade, revelando uma serie de classificações e hierarquizações no contexto da escola e delimitando relações horizontais e verticais entre os atores que participam do espaço escolar. Podemos considerar que os xingamentos constituem um sistema de agressão canalizada (Duarte, 1985) na medida em que permitem compreender como é possível, ou não, administrar as desigualdades presentes

19 Embora o termo mais adequado do ponto de vista técnico seja “orientação sexual”, por indicar o gênero (masculino e feminino) pelo qual uma pessoa se sente atraída física e/ou emocionalmente, o termo mais usado pelos sujeitos da pesquisa é “opção sexual”. 
na escola na expressão de conflitos, negociações e protestos, e não meras expressões destituídas de sentido (Toledo, 1993).

As tênues fronteiras que separam as relações jocosas do insulto moral $^{20}$ (Cardoso de Oliveira, 2008) são percebidas apenas pela mobilização das emoções dos atores envolvidos. A sua frequência é tão constante que, mesmo quando são evidentes as situações em que a fronteira entre piada e as agressões verbais (xingamentos e humilhações) já foi ultrapassada, nota-se uma tendência a naturalizar os conflitos, o que resulta numa desqualificação em relação às situações de violência física, tal como relatado por Abramovay (2002).

Consequentemente, em muitas escolas, as agressões verbais não se constituem como "problemas" para os professores e gestores, que restringem as sanções escolares às situações de confronto físico, ainda assim, dependendo de quem esteja envolvido nelas. O envolvimento de profissionais da escola tende a ocorrer mais para apartar as brigas ou para o acionamento de instituições de segurança, geralmente, guardas municipais e policiais militares.

Tendo em vista a opção dos gestores da escola, na maioria dos casos envolvendo os olhares, xingamentos e insultos, a violência e a agressão física, em deixar passar em branco essas situações sem que haja uma problematização dos seus significados, torna-se corrente que as agressões morais ou físicas se apresentam como os recursos privilegiados para os alunos conseguirem restituir sua imagem pessoal no contexto da escola. Caso sejam bem-sucedidos nas situações de confronto físico, os antes desmoralizados agredidos obtêm reconhecimento entre seus colegas, ganhando prestígio e status, o que legitima a violência como mecanismo de resolução de conflitos de gênero na escola.

Com a presença cada vez maior da sociabilidade on-line na construção das relações de gênero entre os jovens (Petrosillo, 2016; Vasconcelos et al., 2017), essa situação tende a ser potencializada, já que era comum que os alunos filmassem ou fotografassem as brigas para expô-las em aplicativos e redes sociais, através da internet, aumentando o número de espectadores possíveis e criando outro espaço de visibilização dos conflitos, antes invisibilizados pela forma escolar de administrá-los.

${ }^{20}$ Corresponde a um “conceito que realça as duas características principais do fenômeno: (1) trata-se de uma agressão objetiva a direitos que não pode ser adequadamente traduzida em evidências materiais; e, (2) sempre implica uma desvalorização ou negação da identidade do outro” (Cardoso de Oliveira, 2008, p. 136). 


\section{Considerações finais}

A escola constitui-se num campo de tensões que podem ser observadas em diferentes dimensões, quais sejam, as práticas políticas associadas à definição de legislações e de políticas públicas, e as práticas pedagógicas que costumam ser analisadas a partir dos processos de socialização e transmissão de conteúdos.

Neste artigo pretendemos analisar como os conflitos nas escolas estão associados aos processos de delimitação de identidade de gênero. Com isso, como Scott (1989) propôs, esperamos ter colaborado para a compreensão de como as instituições incorporam o gênero em sua organização e funcionamento, assim como o papel que a escola cumpre no processo de generificação que estabelece os modelos de masculinidade e feminilidade na sociedade brasileira.

A partir dos conflitos de gênero que pudemos acompanhar, pôde-se concluir que várias brigas entre os estudantes são motivadas por concepções de masculinidade e feminilidade que se baseiam na dicotomia do sexo, associada aos aspectos biológicos, que são influenciados por uma moralidade que classifica determinados comportamentos sexuais fora do controle social androcêntrico como não legítimos no grupo (Vale de Almeida, 2003), o que reafirma a dicotomia público/doméstico que marca os processos de construção de identidade de gênero no país. Portanto, as interações na escola tendem a reproduzir o binarismo masculino/feminino em todo processo de escolarização. Por não se constituir em um espaço de valorização da diversidade sexual, observam-se inúmeras situações de invisibilização de homossexuais, lésbicas, bissexuais e transgêneros no espaço escolar, que somadas aos insultos e às agressões físicas motivadas por conflitos de gênero acabam por consolidar o heterossexismo, caracterizado pela "promoção incessante, pelas instituições e/ou indivíduos, da superioridade da heterossexualidade e da subordinação simulada da homossexualidade” (Welzer-Lang, 2001, p. 467).

Esses processos atingem de forma diferenciada estudantes e profissionais de educação, mas nota-se que ambos, quando estão na condição de vítimas, não encontram apoio na escola para denunciar as agressões e reivindicar seus direitos. Mesmo sendo um espaço majoritariamente gerido por mulheres, reproduz-se a opressão, o silenciamento da orientação sexual e a submissão do feminino frente ao masculino, reproduzindo o ideário de uma sociedade sexista (Bourdieu, 2011). 
A forma pela qual os conflitos se apresentam na escola é fundamental para o estabelecimento de formas institucionais de administração de conflitos. Em primeiro lugar é preciso compreendê-los em seus contextos e que atores estão envolvidos. Nos casos analisados o que se observou comumente foi que os profissionais que atuam no ambiente escolar (professores, diretores, coordenadores, inspetores, etc.) se dividem em duas posturas: 1) optam por ignorar os conflitos de gênero, considerando que não faria parte de suas responsabilidades intervir nos casos; ou 2) intervêm nos eventos a partir de uma perspectiva de vitimização de uma das partes, que expressa uma naturalização da desigualdade de gênero.

A ausência de mediação dos profissionais da escola nesses eventos representa um reforço de cenários nos quais os conflitos envolvem os próprios estudantes, seja como agressores e vítimas, seja como expectadores dos conflitos. Ao se desconsiderar que "as brigas, conflitos e desavenças representam, muitas vezes, elementos desestruturadores dos grupos de afinidade” (Villas, 2009, p. 105), os profissionais da escola tendem a menosprezar esses processos de interação, sem perceber que pode haver uma relação direta entre os modos pelos quais as crianças e jovens se sociabilizam com as formas de vinculação, e até submissão, em face das demandas da escola.

A ausência de intervenção nos conflitos não é generalizada, mas, quando acontece, expressa uma concepção de interação social sem considerar a dimensão normativa que a constitui (Cardoso de Oliveira, 2010), que está intrinsecamente relacionada a permanentes disputas sobre direitos. Qualquer relação social que envolva interações frequentes e continuadas, que sejam relevantes para os envolvidos, serão marcadas pela explicitação de conflitos em um dado momento.

É preciso lembrar que Simmel (2006) destaca que o caráter democrático da sociabilidade só se constrói a partir da artificialidade do "mundo da sociabilidade”, ou seja, depende da construção de condições sociais que favoreçam a equivalência de posições e status entre os indivíduos que se sociabilizam, já que os grupos tendem a privilegiar processos simétricos de interação.

Lamentavelmente, salientamos que as ações de administração institucional de conflitos mostram-se pouco relacionadas à técnica de construção de regras coletivas, que poderiam possibilitar uma convivência mais democrática e plural. Pelo que vimos, de certa forma, elas tendem a reproduzir medidas repressivas que, de alguma maneira, naturalizam as desigualdades de gênero e legitimam uma visão de mundo sexista. 
Essa situação pode ser caracterizada como uma "violência da escola", nos termos propostos por Charlot (2002), ou seja, uma violência simbólica que atinge os discentes pela forma como os mesmos são tratados. Inicia-se assim um ciclo de violências na instituição escolar. Sob a forma de "violência na escola”, passamos a observar conflitos que se produzem dentro do espaço escolar, mas cuja origem é externa. A escola revela-se um palco para a explicitação de problemas, entre sujeitos ou entre grupos, que poderiam ter ocorrido em qualquer outro local. Essa é a justificativa que se aciona para não administrar os conflitos e legitimar a presença de policiais e/ou guardas municipais no ambiente escolar, sem se avaliar se esses profissionais estão preparados para lidar com os conflitos ou se os procedimentos adotados são adequados aos contextos escolares. ${ }^{21}$ Com isso tem-se o reforço do ciclo, que parece ampliar cada vez mais a manifestação de agravamento dos conflitos.

A construção de estratégias de administração de conflitos mais dialógicas é algo previsto nos documentos que orientam a educação nacional, no entanto observa-se que a redução da conflitividade social esbarra na dificuldade que é o engajamento dos docentes e dos gestores escolares, que muitas vezes não têm qualquer articulação entre a escola e a sociedade, o que poderia transformar o espaço escolar num ambiente mais acolhedor aos estudantes.

Os silenciamentos sobre os conflitos de gênero na escola levam a uma situação em que os sujeitos sociais que compõem o cenário da diversidade sexual sejam apenas o homem versus a mulher. Nesse contexto, a escola acaba por ressaltar o binarismo e transforma em desigualdades substanciais os modelos socialmente aceitos e recomendados para meninos e meninas, sem que os atores se deem conta que a invisibilidade dessas moralidades afeta diretamente os modos de gerenciar as políticas educacionais no que se refere à promoção da igualdade a partir do respeito às diferenças.

Ao fugir das discussões e debates a respeito dos conflitos de gênero, a escola renuncia ao lugar de estabelecimento de uma retórica construída a partir da própria diversidade, repleta de nuances e classificações, que devem espelhar a vivência de alunos e alunas, professores e professoras, gestores e gestoras.

${ }^{21}$ Uma terceira situação se faz presente, a qual Charlot (2002) denomina de “violência à escola”. Trata-se dos eventos relacionados aos danos provocados ao patrimônio escolar, às atividades da instituição escolar e aos insultos e agressões físicas aos docentes. 


\section{Referências}

ABRAMOVAY, M. (Org.). Escola e violência. Brasília: Unesco, 2002.

ABRAMOWICZ, A.; RODRIGUES, T. C.; CRUZ, A. C. J. A diferença e a diversidade na educação. Contemporânea: Revista de Sociologia da UFSCar, São Carlos, v. 2, p. 85-97, 2011.

AUAD, D. Educar meninas e meninos: relações de gênero na escola. São Paulo: Contexto, 2006.

BECKER, H. A pesquisa em escolas urbanas. Enfoques, Rio de Janeiro, v. 12, n. 2, 2013.

BESSA, K. A. M. "Gender trouble”: outra perspectiva de compreensão do Gênero. Cadernos Pagu, Campinas, n. 4, p. 261-267, 1995.

BOURDIEU, P. Sistemas de ensino e sistemas de pensamento. In: BOURDIEU, P. A economia das trocas simbólicas. São Paulo: Perspectiva, 1987. p. 203-230.

BOURDIEU, P. A dominação masculina. 10. ed. Rio de Janeiro: Bertrand, 2011.

BRASIL. Parâmetros Curriculares Nacionais (PCNs). Brasília: MEC/SEF, 1998.

BUTLER, J. Corpos que pesam: sobre os limites discursivos do sexo. In: LOURO, G. L. (Org.). O corpo educado: pedagogias da sexualidade. Belo Horizonte: Autêntica, 2000. p. 151-172.

BUTLER, J. Problemas de gênero: feminismo e subversão da identidade. Rio de Janeiro: Civilização Brasileira, 2003.

CAPUTO, S. G. Educação nos terreiros: como a escola se relaciona com as crianças de candomblé. Rio de Janeiro: Pallas, 2012.

CARDOSO DE OLIVEIRA, L. R. Existe violência sem agressão moral?. Revista Brasileira de Ciências Sociais, São Paulo, v. 23, n. 67, p. 135-146, 2008.

CARDOSO DE OLIVEIRA, L. R. A dimensão simbólica dos direitos e a análise de conflitos. Revista de Antropologia, São Paulo, v. 53, n. 2, p. 451473, 2010. 
CEFAÏ, D. Qu'est-ce qu'une arène publique? Quelques pistes pour une approchepragmatiste. In: CEFAÏ, D.; JOSEPH, I. L'Héritage du pragmatisme: conflits d'urbanité et épreuves de civisme. Paris: Éditions de l’Aube, 2002. p. $51-82$.

CHARLOT, B. A violência na escola: como os sociólogos franceses abordam essa questão. Sociologias, Porto Alegre, n. 8, p. 432-443, 2002.

CONNELL, R. W.; MESSERSCHMIDT, J. W. Masculinidade hegemônica: repensando o conceito. Revista Estudos Feministas, Florianópolis, v. 21, n. 1, p. 241-282, 2013.

DAMATTA, R. Tem pente aí? Reflexões sobre a identidade masculina. In: CALDAS, D. (Org.). Homens: comportamento, sexualidade, mudança. São Paulo: Senac, 1997. p. 31-49.

DAUSTER, T. "Um outro olhar” - entre a antropologia e a educação. Cadernos CEDES, Campinas, v. 18, n. 43, p. 38-45, 1997.

DAUSTER, T. "Sobre etnografia e educação": quais as perspectivas e dilemas?. Revista Espaço, Rio de Janeiro, n. 29, p. 1-15, 2008.

DUARTE, L. F. D. Identidade social e padrões de agressividade verbal em um grupo de trabalhadores urbanos. In: LOPES, J. S. L. (Org.). Culturas e identidade operária: aspectos da cultura da classe trabalhadora. Rio de Janeiro: Marco Zero: UFRJ, 1985. p. 171-201.

EILBAUM, L. “O bairro fala”: conflitos, moralidades e justiça no conurbano bonaerense. São Paulo: Hucitec: Anpocs, 2012.

ERICKSON, F. What makes school ethnography 'ethnographic'?. Anthropology and Education Quarterly, v. 15, p. 51-66, 1984.

FAGUNDES, T. C. P. C. (Org.). Ensaios sobre gênero e educação. Salvador: EDUFBA, 2001.

FISCHER, M. Iran, from religious dispute to revolution. Cambridge: Harvard University Press, 1980. 
GOFFMAN, E. Os quadros da experiência social: uma perspectiva de análise. Petrópolis: Vozes, 2012.

GUEDES, S. L. Por uma abordagem etnográfica dos contextos pedagógicos. In: GUEDES, S.; CIPINIUK, T. (Org.). Abordagens etnográficas sobre educação: adentrando os muros das escolas. Niterói: Alternativa: Faperj, 2014. p. 7-10.

GUSMÃO, N. M. M. Antropologia e educação: origens de um diálogo. Cadernos CEDES, Campinas, v. 18, n. 43, p. 8-25, 1997.

GUSMÃO, N. M. M. Por uma antropologia da educação no Brasil. ProPosições, Campinas, v. 21, n. 2, p. 259-265, 2010.

JACKSON, P. W. Life in classrooms. New York: Holt, Rinehart and Winston, 1968.

KANT DE LIMA, R. Polícia, justiça e sociedade no Brasil: uma abordagem comparativa dos modelos de administração de conflitos no espaço público. Revista de Sociologia e Política, Curitiba, v. 1, n. 13, p. 23-38, 1999.

KANT DE LIMA, R. Administração de conflitos, espaço público e cidadania: uma perspectiva comparada. Civitas: Revista de Ciências Sociais, Porto Alegre, v. 1, n. 2, p. 11-16, 2001.

LOURO, G. L. Educação e gênero: a escola e a produção do feminino e do masculino. In: SILVA, L. H. da; AZEVEDO, J. C. de. Reestruturação curricular: teoria e prática no cotidiano da escola. Petrópolis: Vozes, 1995. p. 172-182.

LOURO, G. L. Pedagogias da sexualidade. In: LOURO, G. L. (Org.). O corpo educado: pedagogias da sexualidade. Belo Horizonte: Autêntica, 2000. p. 7-34.

LOURO, G. L.; NECKEL, J. F.; GOELLNER, S. V. (Org.). Corpo, gênero e sexualidade: um debate contemporâneo na educação. Petrópolis: Vozes, 2003.

MAC AN GHAILL, M. The making of men: masculinities, sexualities and schooling. Buckingham: Open University Press, 1994. 
MAIA, B. "Matéria de caderno": jocosidade e evitação nas aulas de ensino religioso em uma escola pública. In: GUEDES, S.; CIPINIUK, T. (Org.). Abordagens etnográficas sobre educação: adentrando os muros das escolas. Niterói: Alternativa: Faperj, 2014a. p. 163-183.

MAIA, B. Vida de escola: autoridade, carisma e performance em uma escola pública. 2014. Dissertação (Mestrado em Antropologia)-Instituto de Ciências Humanas e Filosofia, Universidade Federal Fluminense, Niterói, 2014b.

MARTINO, W. Boys and literacy: exploring the construction of hegemonic masculinities and the formation of literate capacities for boys in the English classroom. English in Australia, Melbourne, n. 112, p. 11-24, 1995.

MCLAREN, P. Rituais na escola: em direção a uma economia política de símbolos e gestos na educação. Petrópolis: Vozes, 1992.

MIRANDA, A. P. M. "Motivo presumido: sentimento": identidade religiosa e estigmatização escolar no Rio de Janeiro. Dilemas, Rio de Janeiro, v. 1, série especial, p. 139-164, 2015.

MIRANDA, A. P. M.; MAIA, B. Ensinar religião ou falar de religião? Controvérsias em escolas públicas do Rio de Janeiro. Revista Teias, Rio de Janeiro, v. 15, n. 36, p. 80-97, 2014.

MONTERO, P. Controvérsias religiosas e esfera pública: repensando as religiões como discurso. Religião e Sociedade, Rio de Janeiro, v. 32, n. 1, p. 167-183, 2012.

MOTA, F. R. Cidadãos em toda parte ou cidadãos à parte?: demandas de direitos e reconhecimento no Brasil e na França. Rio de Janeiro: Consequência, 2014.

NANES, G.; LEITÃO, M. R. F. A.; QUADROS, M. T. (Org.). Gênero, educação e comunicação. Recife: Editora Universitária da UFRPE: Editora UFPE, 2016.

NÓVOA, A. Para uma análise das instituições escolares. Lisboa: FPCEUL, 1990.

OGBU, J. U. School ethnography: a multilevel approach. Anthropology and Education Quarterly, v. 12, n. 1, p. 3-29, 1981. 
PINTO, N. M. Juventude, conflitos e consensos: estudo de caso em duas escolas. In: GUEDES, S.; CIPINIUK, T. (Org.). Abordagens etnográficas sobre educação: adentrando os muros das escolas. Niterói: Alternativa: Faperj, 2014. p. 83-96.

PETROSILLO, I. R. Esse nu tem endereço: o caráter humilhante da nudez e da sexualidade feminina em duas escolas públicas. 2016. Dissertação (Mestrado em Antropologia)-Instituto de Ciências Humanas e Filosofia, Universidade Federal Fluminense, Niterói, 2016.

PRÁ, J. R.; CEGATTI, A. C. Gênero, educação das mulheres e feminização do magistério no ensino básico. Revista Retratos da Escola, Brasília, v. 10, n. 18, p. 215-228, jan./jun. 2016.

RADCLIFFE-BROWN, A. R. Sistemas africanos de parentesco e casamento - Introdução. In: MELATTI, J. C. (Org.). Radcliffe-Brown: antropologia. São Paulo: Ática, 1978. p. 59-161.

RESENDE, J. M. A sociedade contra a escola?: a socialização política escolar num contexto de incerteza. Lisboa: Instituto Piaget, 2010.

ROSISTOLATO, R. P. R. Orientação sexual com “jeitinho” brasileiro: uma análise antropológica da intervenção escolar nasocialização afetivo-sexual dos adolescentes. Rio de Janeiro: UFRJ/IFCS, 2007.

SCOTT, J. W. Gender: a useful category of historical analyses. In: SCOTT, J. W. Gender and the politics of history. New York: Columbia University Press, 1989. p. 28-52.

SCOTT, J. W. Gênero: uma categoria útil de análise histórica. Educação e Realidade, Porto Alegre, v. 20, n. 2, p. 71-100, jul./dez. 1995.

SIMMEL, G. Sociologia. São Paulo: Ática, 1983.

SIMMEL, G. Questões fundamentais da sociologia. Rio de Janeiro: Jorge Zahar, 2006.

TOLEDO, L. H. Por que xingam os torcedores de futebol?. Cadernos de Campo, São Paulo, n. 3, p. 20-29, 1993. 
TOSTA, S. Antropologia e educação: interfaces em construção e as culturas na escola. Inter-Legere, Natal, n. 9, p. 234-252, 2011.

VALE DE ALMEIDA, M. Senhores de si: uma interpretação antropológica da masculinidade. 2. ed. Lisboa: Fim de Século, 1995.

VALE DE ALMEIDA, M. Antropologia e sexualidade: consensos e conflitos teóricos em perspectiva histórica. In: FONSECA, L.; SOARES, C.; VAZ, J. M. (Org.). A sexologia, perspectiva multidisciplinar: vol. II. Coimbra: Quarteto, 2003. p. 53-72.

VARGAS, J. R. Meninas não brigam? Posturas diferenciadas na escola contemporânea. Espaço do Currículo, João Pessoa, v. 2, n. 2, p. 167-180, 2010.

VASCONCELOS, O. S. et al. Vitrine virtual: comunicação, práticas corporais e sociabilidade no Grindr. Verso e Reverso, São Leopoldo, v. 31, n. 76, p. 3645, 2017.

VILLAS, S. Formas de sociabilidade entre alunos de uma escola de Ensino Médio/Técnico. 2009. Dissertação (Mestrado em Educação)-Faculdade de Educação, Universidade Federal de Minas Gerais, Belo Horizonte, 2009.

WARREN, S. Who do these boys think they are? An investigation into the construction of masculinities in a primary classroom. International Journal of Inclusive Education, v. 1, n. 2, p. 207-222, 1997.

WELZER-LANG, D. A construção do masculino: dominação das mulheres e homofobia. Revista Estudos Feministas, Florianópolis, v. 9, n. 2, p. 460-482, 2001.

WILLIS, P. Aprendendo a ser trabalhador: escola, resistência e reprodução social. Porto Alegre: Artes Médicas, 1991. 